\title{
Mechanism and Optimization of a Novel Automobile Pneumatic Suspension Based on Dynamic Analysis
}

\author{
Zhibo Sun ${ }^{1}$, Yan Shi ${ }^{2}$, Na Wang ${ }^{1, *}$, Jian Zhang ${ }^{2}$, Yixuan Wang ${ }^{2, *}$ and Shaofeng Xu ${ }^{2}$ (D) \\ 1 Engineering Training Center, Beihang University, Beijing 102206, China; sunzb@buaa.edu.cn \\ 2 School of Automation Science and Electrical Engineering, Beihang University, Beijing 100191, China; \\ yesoyou@gmail.com (Y.S.); maliano@cis.org.cn (J.Z.); xusf@buaa.edu.cn (S.X.) \\ * Correspondence: lion_na987@buaa.edu.cn (N.W.); magic_wyx@buaa.edu.cn (Y.W.)
}

check for updates

Citation: Sun, Z.; Shi, Y.; Wang, N.;

Zhang, J.; Wang, Y.; Xu, S. Mechanism and Optimization of a Novel Automobile Pneumatic Suspension Based on Dynamic Analysis. Electronics 2021, 10, 2232. https:/ / doi.org/10.3390/electronics10182232

Academic Editor: Nikolay Hinov

Received: 13 August 2021

Accepted: 9 September 2021

Published: 11 September 2021

Publisher's Note: MDPI stays neutral with regard to jurisdictional claims in published maps and institutional affiliations.

Copyright: (c) 2021 by the authors. Licensee MDPI, Basel, Switzerland. This article is an open access article distributed under the terms and conditions of the Creative Commons Attribution (CC BY) license (https:// creativecommons.org/licenses/by/ $4.0 /)$.
Abstract: Pneumatic suspension is the most significant subsystem for an automobile. In this paper, a simplified and novel pneumatic spring structure with only a conical rubber surface is presented and designed to reduce the influence of external factors besides the pneumatic. The nonlinear stiffness of the pneumatic spring is analyzed based on the ideal gas model and material mechanics. Natural frequency analysis and the transmission rate of the pneumatic suspension are obtained as two effect criteria for the dynamic model. The vibration isolation system platform is established in both simulation and prototype tests. With the results from the simulation, the rules of the pneumatic suspension are analyzed, and the optimal function of mass and pressure is achieved. The experiment results show the analysis of the simulation to be effective. This achievement will become an important basis for future research concerning precise active control of the pneumatic suspension in vehicles.

Keywords: pneumatic spring; vibration isolation; dynamic model; natural frequency

\section{Introduction}

In vehicle dynamics, the suspension system is an important part of the composition for driving comfort and stability [1]. Pneumatic springs have been widely used in automobiles as well as in maglev and rail vehicles [2,3]. As one of the core components of automobile vibration isolation systems, a pneumatic spring can change the stiffness in response to driving conditions by changing the gas pressure inside the air spring volume [4]. This adjustment has a direct impact on automobile comfort. Compared with the traditional spring mechanism, a pneumatic spring has the advantages of low natural frequency, variable stiffness range, and high energy storage [5-8], and has better vertical vibration isolation $[9,10]$. Moreover, the nonlinear stiffness and damping properties can enhance the attenuation of ride quality and handling performance for large payload variations [11].

In recent years, great achievements have been made in the research of pneumatic springs. F Chang et al. analyzed the dynamic model of an air spring used in vehicles through MATLAB/Simulink and ADAMS [12]. Hengmin Qi et al. developed an electronic-controlled pneumatic spring to improve the stability and ride comfort of a 9DOF vehicle [13]. Chai studied the mechanical characteristics of automobile air springs based on the finite element method [14]. Zhong studied the nonlinearity of the pneumatic vibration isolation system through frequency analysis [15]. M.M. Moheyeldein analyzed the parameters of air spring and passive suspensions and investigated the influences of air spring model parameters on vehicle dynamics [16]. Li Yuyan designed a pneumatic spring with a natural frequency below $1 \mathrm{~Hz}$ and evaluated the vibration isolation effect through vibration isolation transmissibility and vibration isolation efficiency [17]. Yin et al. developed a predictive method of effective area of rolling lobe air spring for vehicles [18]. Active suspension technology is also under development with control methods such as T-S fuzzy [19], model predictive control (MPC) [20,21], deep learning [22], sliding mode [23], 
and BP neural networks [24] applied in engine systems [25], steering systems [26], and driving systems [27] of vehicles.

In this study, a simple and novel structure of a pneumatic spring is proposed. The stiffness of the spring is analyzed, and a dynamic model of the vibration isolation system is established based on the ideal gas equation and material mechanics [28]. Based on the results of our simulation, the influence of the pneumatic spring parameters on the vibration isolation system performance is presented, showing that optimal function has been achieved. Finally, a summary of the results and conclusions is presented.

\section{Dynamic Model of the Pneumatic Vibration System}

\subsection{Nomenclature Table for Main Parameters}

For convenient application, the main symbols of the pneumatic spring parameters are shown in Table 1.

Table 1. Nomenclature table for the main parameters of the pneumatic spring.

\begin{tabular}{cccc}
\hline Symbol & Explanation & Symbol & Explanation \\
\hline$p_{\mathrm{g}}$ & The absolute pressure of & $k_{\mathrm{p}}$ & The stiffness of the air \\
$V$ & pneumatic spring & $k_{\mathrm{x}}$ & The stiffness of rubber \\
$m_{\mathrm{g}}$ & The gas volume in cavity & $k$ & The stiffness of the spring \\
$A_{\mathrm{ef}}$ & The gas mass & $x$ & Displacement of the floating \\
$m_{\mathrm{s}}$ & The effective area & $x$ & platform \\
$c$ & Mass of the payload $(\mathrm{kg})$ & $x_{\mathrm{b}}$ & Displacement of the vibration \\
\hline
\end{tabular}

\subsection{Structure of the Pneumatic Spring}

Three types of springs can be used for vehicle vibration isolation systems, but rolling lobe air springs (RLAS) are commonly used in vehicle suspensions for better transmission performance [29]. In this study, to simplify the model and analyze the mechanism of the pneumatic characteristic directly, a simple and novel pneumatic spring structure is presented, and the structure sketch and 3D model of the pneumatic spring are shown in Figure 1.

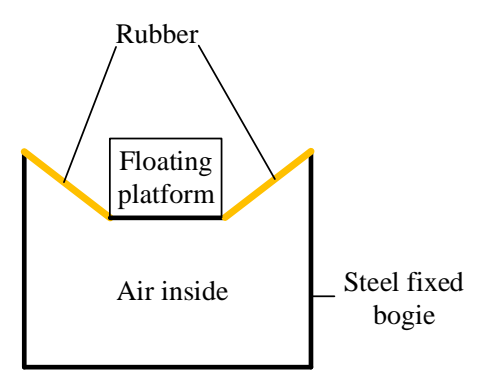

(a)

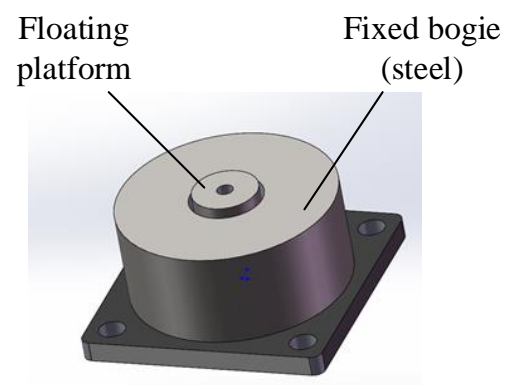

(b)

Figure 1. The novel pneumatic spring. (a) Sketch of the pneumatic spring; (b) 3D model of the pneumatic spring.

The nonlinear characteristic of rubber with multi-layers of composite materials of different thicknesses and different original pressures is difficult to analyze. In the structure shown in Figure 1, the floating platform is connected to the fixed bogie with a conical rubber surface. The influence of the nonlinear rubber is limited by the simple structure. 


\subsection{Stiffness Analysis of the Pneumatic Spring}

For the classical model of a pneumatic spring in the literature, the characteristic can be calculated using the ideal gas equation:

$$
p_{g} V=m_{g} R T
$$

where $p_{g}$ denotes the absolute pressure of the pneumatic spring, $V$ means the gas volume in the cavity, $m_{g}$ is the gas mass, $R$ is the molar gas constant, and $T$ means the temperature in the cavity. Air molecule interaction and volume are ignored in the ideal gas model, and the ideal gas equation is suitable for an environment under $10 \mathrm{MPa}$ with normal temperature [30]. Compared with other models, such as the van der Waals equation, the ideal gas equation reduces the amount of calculation involved while ensuring the reliability of the results.

According to the parameters shown in Figure 2, the volume of the air spring can be calculated as:

$$
V=\pi \frac{D_{2}^{2}}{4} L_{1}+\int_{0}^{x} \pi\left(\frac{D_{1}}{2}+\left(\frac{D_{2}-D_{1}}{2 x}\right) h\right)^{2} d h
$$

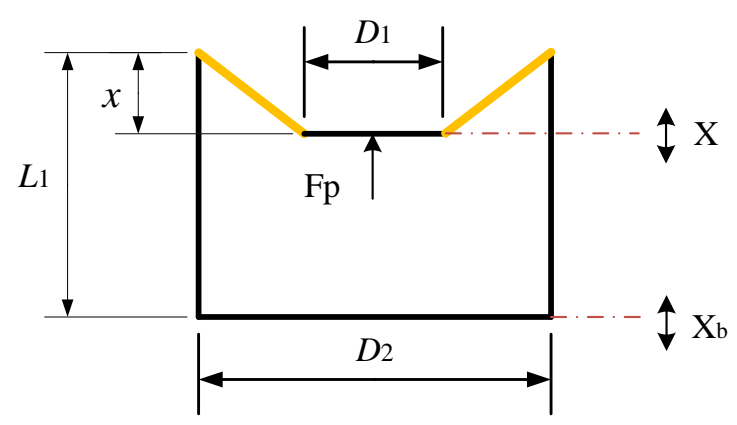

Figure 2. Parameters of the pneumatic spring.

The result can be integrated as:

$$
V=\pi \frac{D_{2}^{2}}{4} L_{1}+\pi \frac{D_{1}^{2}+D_{2}^{2}+D_{1} D_{2}}{12} x
$$

where $L_{1}, D_{1}$, and $D_{2}$ are the geometric parameters of the air spring cavity. $L_{1}$ denotes the length of the air spring cavity, $D_{1}$ is the diameter of the floating platform, $D_{2}$ is the diameter of the fixed platform, and $x$ is the floating displacement. With the new index $\varepsilon$ and the effective area $A_{e f}$ introduced, the equation can be simplified as:

$$
V=\frac{A_{e f}\left(3 L_{1}+\left(\varepsilon^{2}+\varepsilon+1\right) x\right)}{4}
$$

where $\varepsilon=D_{1} / D_{2}$, and the effective area $A_{e f}$ can be calculated as $A_{e f}=\pi\left(\frac{D_{2}}{2}\right)^{2}$. Through this derivation, the stiffness characteristic of the pneumatic element can be obtained as:

$$
k_{k}=\frac{\partial F_{p}}{\partial x}=\frac{\partial\left(P_{g}-P_{0}\right) A_{e f}}{\partial x}=\frac{\partial\left(P_{g}-P_{0}\right)}{\partial x} A_{e f}+\frac{\partial A_{e f}}{\partial x}\left(P_{g}-P_{0}\right)
$$

where $k_{k}$ denotes the stiffness of the air, $F_{p}$ is the vertical force, and $P_{0}$ is the pressure of the atmosphere. The gas condition change determines that it is polytrophic; therefore, the following equation is valid:

$$
p_{g} V^{\lambda}=\text { const }
$$

where $\lambda$ is the polytrophic coefficient. If the internal temperature is constant, then $\lambda=1$. If part of the gas cannot complete the heat exchange process within a short time or there is 
not much heat exchange and it is regarded as an adiabatic process, then $\lambda$ is recorded as 1.4. From Equation (2) to Equation (6), Equation (7) is differentiated as follows:

$$
\frac{\partial P_{g}}{\partial x}=-\frac{P_{g} \lambda}{V} \frac{\partial V}{\partial x}=-\frac{P_{g} \lambda A_{e f}\left(\varepsilon^{2}+\varepsilon+1\right)}{4 V}
$$

In this pneumatic spring model, the effective area is a constant. Referring to Equations (5) and (7), the stiffness of the air can be expressed as:

$$
k_{p}=-\frac{P_{g} \lambda A_{e f}^{2}\left(\varepsilon^{2}+\varepsilon+1\right)}{4 V}
$$

\subsection{Stiffness Analysis of the Rubber}

In this pneumatic spring, the rubber is the connector between the pneumatic cavity and the fixed bogie. Within the structure, the influence of the rubber's nonlinear characteristic is limited and mainly affects the boundary stiffness of the spring. As shown in Figure 3, the rubber has a conical surface and can be regarded as a series of ring springs. It is assumed that the rubber material presents a smooth characteristic. Based on the material mechanics, the stiffness of the rubber can be integrated as:

$$
k_{x}=\frac{1}{\sum_{i=1}^{n} \frac{1}{\Delta k_{x}}}=\frac{1}{\sum_{i=1}^{n} \frac{\Delta l}{E S_{i}}}=\frac{1}{\sum_{i=1}^{n} \frac{\Delta l}{E\left(\left(D_{1}+\frac{D_{2}-D_{1}}{n} i+\delta\right)^{2}-\left(D_{1}+\frac{D_{2}-D_{1}}{n}\right)^{2}\right)}}
$$

where $E$ denotes Young's modulus of the rubber, $l$ is the vertical elongation of the rubber, $S$ is the interface area of the rubber, $x_{0}$ is the activating length of the rubber spring, $\delta$ is the thickness of the rubber, $\Delta l$ is an element of the rubber spring, and $n$ is the number of the element that can be calculated as $n=l / \Delta l$. The boundary stiffness is considered as the parallel of the air and the rubber. Thus, the stiffness of the pneumatic spring can be determined from the aforementioned equations as follows:

$$
k=\left\{\begin{array}{cc}
k_{p} & x \leq x_{0} \\
k_{x}+k_{p} & x>x_{0}
\end{array}\right.
$$

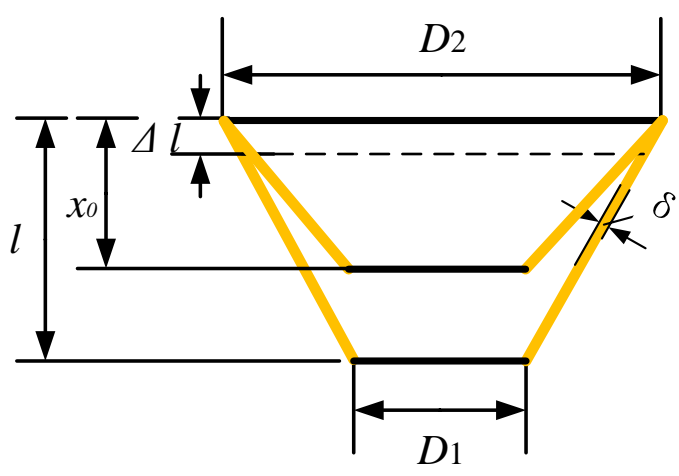

Figure 3. Parameters of the rubber connector.

\section{Analysis of the Vehicle Pneumatic Vibration Isolation Model}

\subsection{Dynamic Model Analysis}

The schematic diagram of the $1 / 4$ vehicle pneumatic suspension model is presented in Figure 4. In this system, a 2-DOF suspension model is established. It consists of a sprung mass, referring to the frame of the vehicle that is supported by the pneumatic suspension. The pneumatic suspension and the wheel assembly are connected to the axle. A simple representation of the wheel is used that includes the tire stiffness and damping. Pavement 
vibration acts on the wheel directly. The dynamic model of the system can be established as:

$$
\left\{\begin{array}{c}
m_{s} \ddot{x}+c\left(\dot{x}-\dot{x}_{b}\right)+k\left(x-x_{b}\right)=0 \\
m_{\mathrm{a}} \ddot{x}_{b}+c_{w}\left(\dot{x}_{b}-\dot{x}_{a}\right)+k_{w}\left(x_{b}-x_{a}\right)+c\left(\dot{x}_{b}-\dot{x}\right)+k\left(x_{b}-x\right)=0
\end{array}\right.
$$

where $m_{s}$ is the mass of the $1 / 4$ frame of the vehicle; $m_{a}$ is the mass of the axle; $x_{b}$ denotes the displacement from the axle; $x_{a}$ is the displacement of the pavement; $k_{w}$ and $c_{w}$ are the stiffness and the damping of the wheel assembly, respectively; and $C$ is the damping of the pneumatic spring. In the pneumatic system, an air inlet is the key component of air spring damping. According to hydrodynamics and the flow characteristics of the air inlet, the damping of the pneumatic spring can be expressed as:

$$
c=\dot{m}_{g}=s v \sqrt{2 g \rho\left(\dot{p}_{q}-\dot{p}_{g}\right)}
$$

where $s$ is the area of the air inlet, $v$ is the air velocity through the air inlet, $g$ is the gravitational acceleration, $\rho$ is the air density, and $p_{q}$ is the air pressure out of the air inlet. Based on Equation (12), $c$ is a variable changed by the parameters $v, p_{q}$, and $p_{g}$. In the passive spring, the air velocity through the air inlet is zero, so the damping of the spring will be ignored.

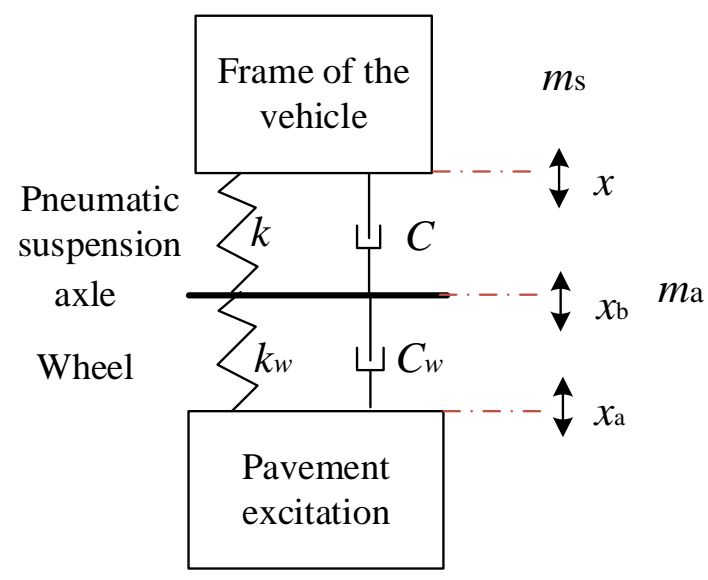

Figure 4. The schematic diagram of the $1 / 4$ vehicle pneumatic suspension.

\subsection{Natural Frequency Analysis}

Equation (11) can be translated in the matrix form as:

$$
\left[\begin{array}{ccc}
m_{s} & 0 & 0 \\
0 & m_{a} & 0 \\
0 & 0 & 0
\end{array}\right]\left[\begin{array}{c}
\ddot{x} \\
\ddot{x}_{b} \\
\ddot{x}_{a}
\end{array}\right]+\left[\begin{array}{ccc}
C & -C & 0 \\
-C & C+C_{w} & -C_{w} \\
0 & 0 & 0
\end{array}\right]\left[\begin{array}{c}
\dot{x} \\
\dot{x}_{b} \\
\dot{x}_{a}
\end{array}\right]+\left[\begin{array}{ccc}
k & -k & 0 \\
-k & k+k_{w} & -k_{w} \\
0 & 0 & 0
\end{array}\right]\left[\begin{array}{c}
x \\
x_{b} \\
x_{a}
\end{array}\right]=0
$$

Additionally, it can also be simplified as:

$$
[\boldsymbol{M}] \ddot{\boldsymbol{X}}+[\boldsymbol{C}] \dot{\boldsymbol{X}}+[\boldsymbol{K}] \boldsymbol{X}=0
$$

Damping of the system can be ignored because it has minimal impact on the natural frequency of the damping. The free vibration can be decomposed into the superposition of a series of simple harmonic vibrations, and the solution of the above equation can be expressed as:

$$
\boldsymbol{X}=[\boldsymbol{\varphi}] e^{j \omega t}
$$


where $\omega$ is the circular frequency of the system and $\varphi$ denotes the amplitude vector. The dynamic function can be changed to:

$$
\left([\boldsymbol{K}]-\omega^{2}[\boldsymbol{M}]\right)[\boldsymbol{\varphi}]=0
$$

The circular frequency can be solved as the square root of the eigenvalues of the matrix $[M]-1^{*}[K]$. The $i$ th natural frequency will be obtained as: $\omega_{\mathrm{i}} /(2 \pi)$.

\subsection{Vibration Isolation Efficiency Analysis}

The vibration isolation effect of a nonlinear vibration isolation system is evaluated using its transmission rate, which is defined as the ratio of corresponding vibration energy before and after the vibration isolation system [31]. The expression can be presented as:

$$
T_{d}=\sqrt{E\left[\dot{x}^{2}\right] / E\left[\dot{x}_{b}^{2}\right]}
$$

where $E\left[\dot{x}^{2}\right]$ and $E\left[\dot{x}_{b}^{2}\right]$ denote the mean square of the frame and pavement velocity. The vibration isolation efficiency can be expressed as:

$$
T=\left(1-T_{d}\right) \times 100 \frac{0}{0}
$$

\section{Simulation of the Pneumatic Spring Working Process}

\subsection{Establishment of the Simulation}

In order to study the influence of different parameters of the pneumatic spring on vibration isolation performance, a test model for the pneumatic vibration isolation system is established. In the test system shown in Figure 5, the wheel assembly system is neglected. The vibration signal from the vibration exciter simulates the vibration from the axle. The pneumatic spring is connected to a vibration exciter, an air compressor, and a payload. The air compressor controls the absolute pressure of the pneumatic spring. The effect is reflected in the performance of the payload vibration.

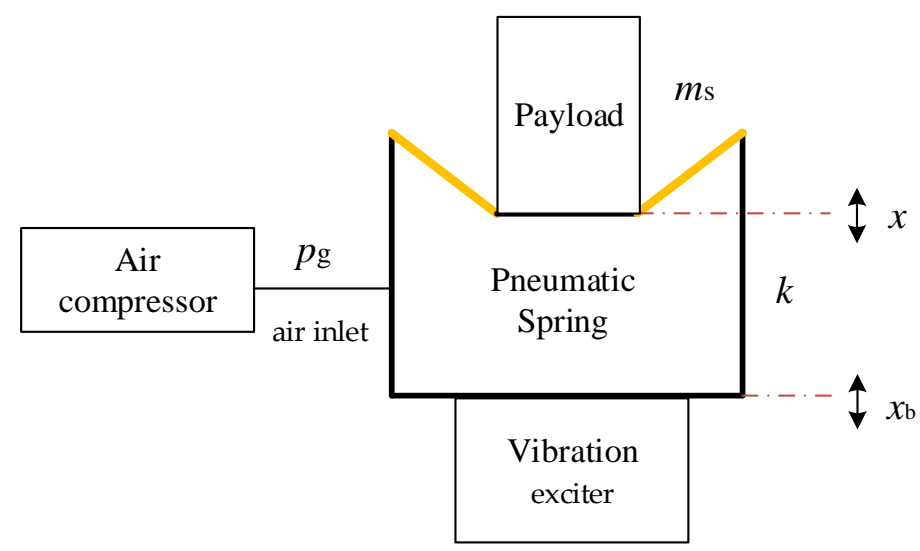

Figure 5. The test model of the pneumatic vibration isolation.

During the real work state, the pneumatic spring equals a passive suspension. The damping of the system is ignored. The analysis model of the pneumatic spring working process is set up in a MATLAB/Simulink environment. According to Equations (10), (11), (16) and (17), four integrated computing modules are established, which are dynamic analysis, natural frequency analysis, transmission rate analysis, and rubber stiffness analysis. In this simulation, five parameters, including $L_{1}, D_{1}, D_{2}, m_{g}$ (directly influence the pressure $\left.p_{g}\right)$, and $m_{s}$, are set as input variables. The evaluating values such as velocity, displacement, natural frequency, and transmission rate are the outputs of the system. 


\subsection{Pressure and Signal Frequency Analysis in Simulation}

Based on the designed parameters of the pneumatic spring and the estimated vehicle weight, the initial state of the simulation is presented in Table 2 .

Table 2. Initial state of the simulation.

\begin{tabular}{ccc}
\hline Parameters & Description (Unit) & Values \\
\hline$L_{1}$ & length of the air spring cavity $(\mathrm{mm})$ & 46 \\
$D_{1}$ & diameter of the floating platform $(\mathrm{mm})$ & 44 \\
$D_{2}$ & diameter of the fixed platform $(\mathrm{mm})$ & 80 \\
$M_{\mathrm{s}}$ & Mass of the payload $(\mathrm{kg})$ & 300 \\
\hline
\end{tabular}

Based on the road roughness levels defined in GB7031-1986, levels A, B, C, and D, with random road excitation at speeds of 120,70 , and $30 \mathrm{~km} / \mathrm{h}$, are in the mid-frequency range, and the normal frequency is under $100 \mathrm{~Hz}$ [32]. In the first simulation, the frequency of the signal is set as $50 \mathrm{~Hz}$, and the amplitude is $5 \mathrm{~mm}$. To analyze the pressure influence, the absolute pressure of the pneumatic spring is set at $5,6,7$, and 8 bar, respectively. The simulation time is $1 \mathrm{~s}$ with 50 cycles, and the simulation results are shown in Figure 6.
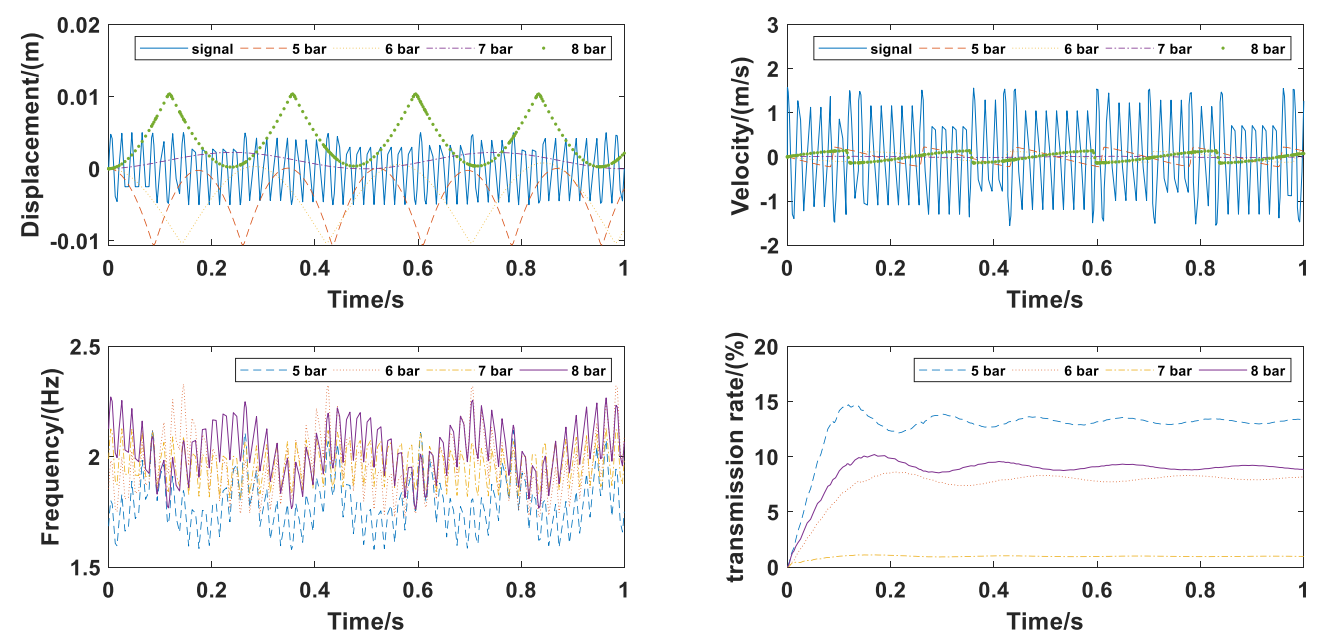

Figure 6. Simulation results under $50 \mathrm{~Hz}$, with $5 \mathrm{~mm}$ amplitude vibration.

As can be seen in the displacement comparison in Figure 6, the curve of 7 bar shows the smoothest performance. The curves of 5 and 6 bar touch below rubber deformation, and the curve of 8 bar touches above rubber deformation. The natural frequency of the system change is not obvious with different pressures. The natural frequency is around $2 \mathrm{~Hz}$.

The maximum velocity fluctuations of $5,6,7$, and 8 bar are $0.450,0.248,0.033$, and $0.282(\mathrm{~m} / \mathrm{s})$, respectively, which are much lower than that of the signal vibration at 3.127. Moreover, in the diagram of transmission rates, a pressure of 7 bar reaches $0.97 \%$, which is much lower than the rates of $13.4 \%, 8.18 \%$, and $8.85 \%$ reached by 5,6 , and 8 bar, respectively.

The results show that the pneumatic spring has a great effect on isolation under $50 \mathrm{~Hz}$ with $5 \mathrm{~mm}$ amplitude vibration on a $300 \mathrm{~kg}$ payload; therefore, $7 \mathrm{bar}$ is a suitable pressure in this situation. However, the natural frequency changed little with the pressure.

In order to analyze the effect of different vibration frequencies, the frequency of the signal is changed to $10 \mathrm{~Hz}$. As can be seen in Figure 7, compared with results from $50 \mathrm{~Hz}$, the displacement and the natural frequency show little difference. The maximum velocity fluctuations of the signal drops to $0.629(\mathrm{~m} / \mathrm{s})$, and that of the $5,6,7$, and 8 bar pressures are $0.484,0.212,0.062$, and $0.287(\mathrm{~m} / \mathrm{s})$, respectively. The final transmission rates are raised to $65.65 \%, 28.62 \%, 7.34 \%$, and $41.55 \%$, respectively. The simulation results show that for the 
two important criteria-isolation velocity and transmission rate-the performance under $10 \mathrm{~Hz}$ vibration is worse than under $50 \mathrm{~Hz}$ vibration.
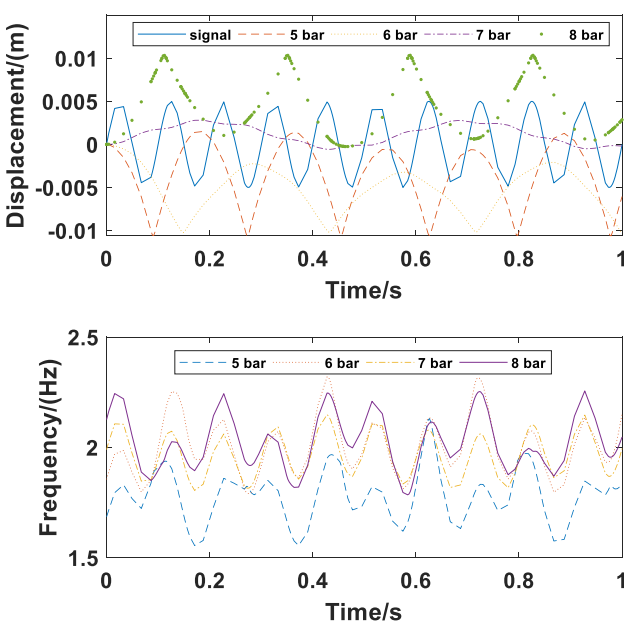
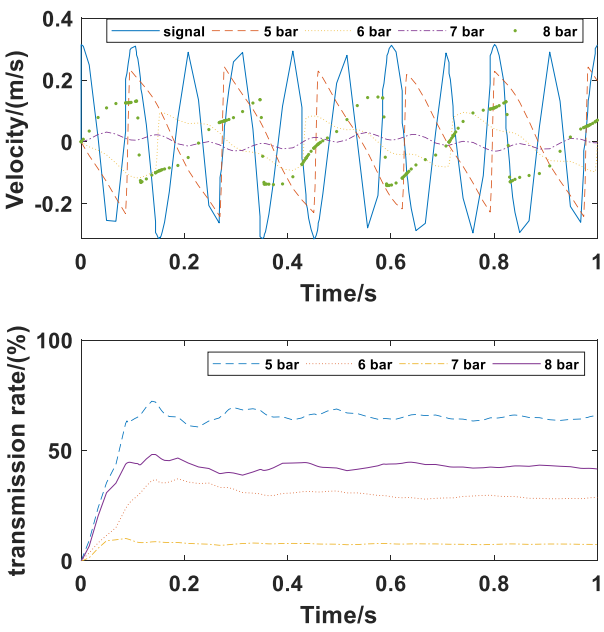

Figure 7. Simulation results under $10 \mathrm{~Hz}$, with $5 \mathrm{~mm}$ amplitude vibration.

When the frequency of the signal is lowered to $2 \mathrm{~Hz}$, which is around the natural frequency of the system, and the simulation time is lengthened to $5 \mathrm{~s}$ (Figure 8), the displacement of the payload changes little when compared with the above results. The maximum velocity fluctuation of the signal drops to $0.127(\mathrm{~m} / \mathrm{s})$, and that of the 5, 6, 7, and 8 bar pressures are $0.487,0.408,0.336$, and $0.521(\mathrm{~m} / \mathrm{s})$, respectively. All the final transmission rates increase beyond $100 \%$. In this environment, the pneumatic spring no longer has any effect on vibration isolation.
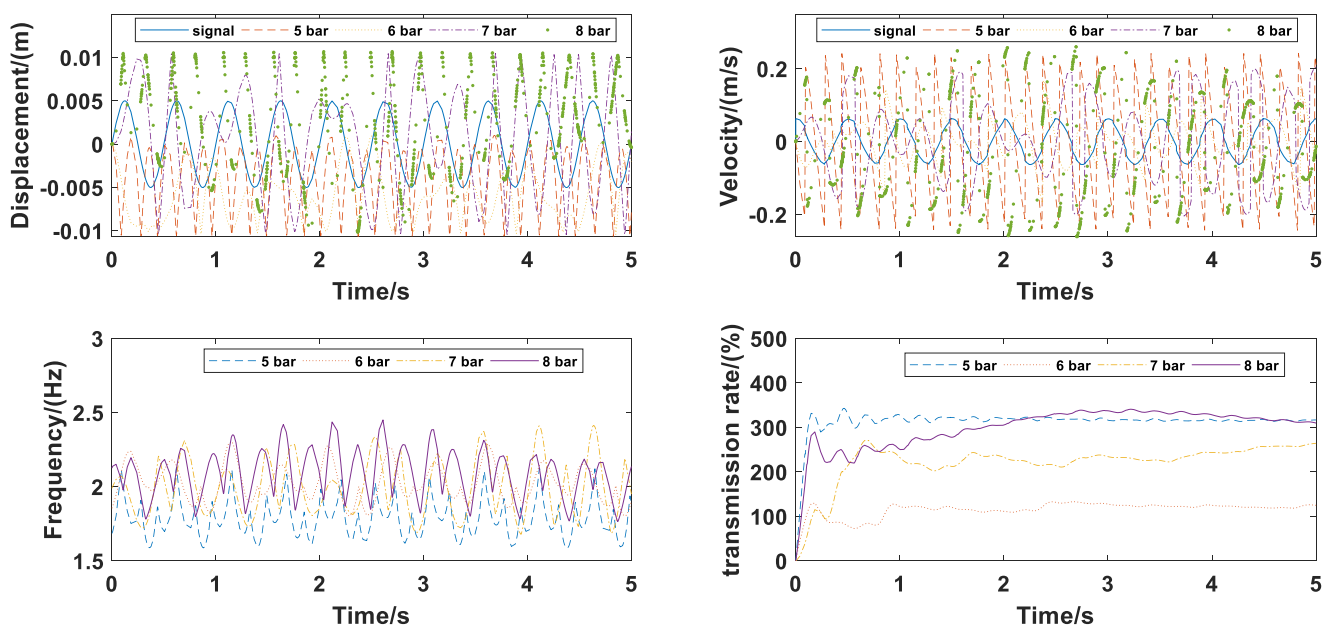

Figure 8. Simulation results under $2 \mathrm{~Hz}$, with $5 \mathrm{~mm}$ amplitude vibration.

Raising the frequency of the signal to $100 \mathrm{~Hz}$, as can be seen in Figure 9, and compared with the results above, the displacement and the natural frequency show little difference. The maximum velocity fluctuation of the signal is $6.28(\mathrm{~m} / \mathrm{s})$, and that of the $5,6,7$, and 8 bar pressures are $0.452,0.227,0.03$, and $0.286(\mathrm{~m} / \mathrm{s})$, respectively. All the final transmission rates drop below $8 \%$. The pneumatic spring performs better than before on isolation velocity and transmission rate. 

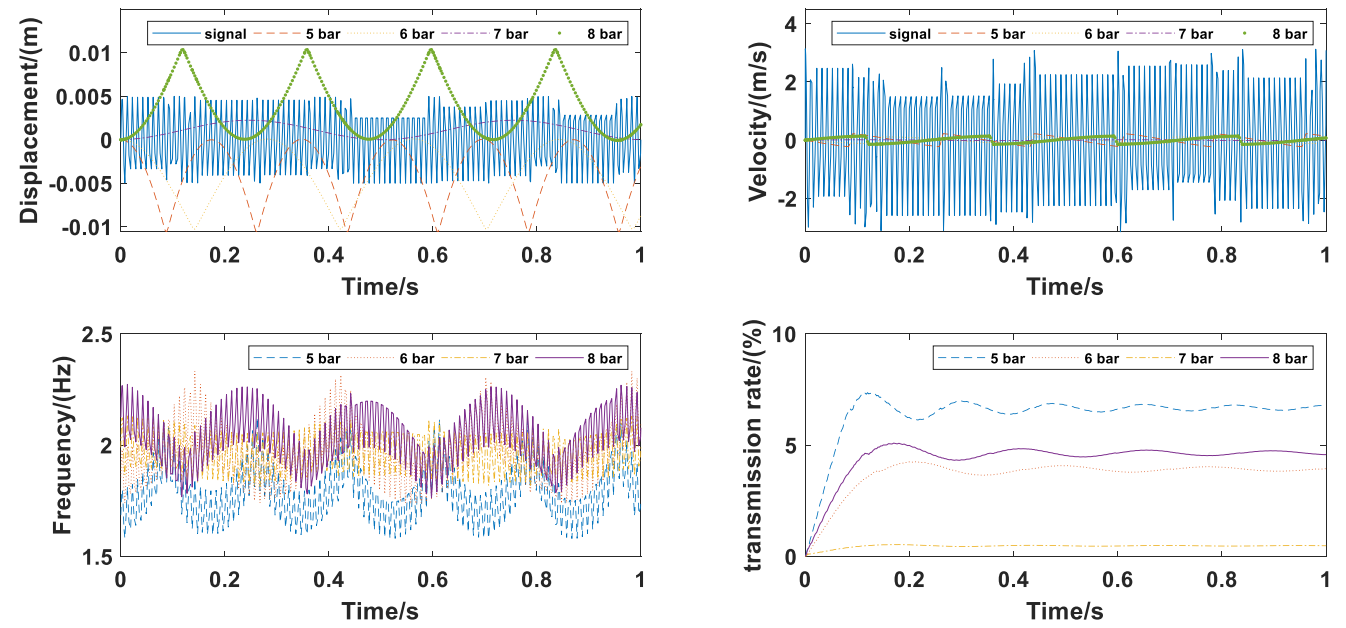

Figure 9. Simulation results under $100 \mathrm{~Hz}, 5 \mathrm{~mm}$ amplitude vibration.

To analyze the transmission rates under different frequency vibrations, unequal piecewise frequency vibrations of 2,3,5,20,40,60, and $80 \mathrm{~Hz}$ are introduced to the simulation. As can be seen in Figure 10, with a $300 \mathrm{~kg}$ payload, the simulation results prove that the pneumatic spring performs better as the vibration frequency increases and loses efficacy (transmission beyond $100 \%$ ) as the vibration frequency drops to $3 \mathrm{~Hz}$. A bar of 7 is a suitable pressure for this situation.

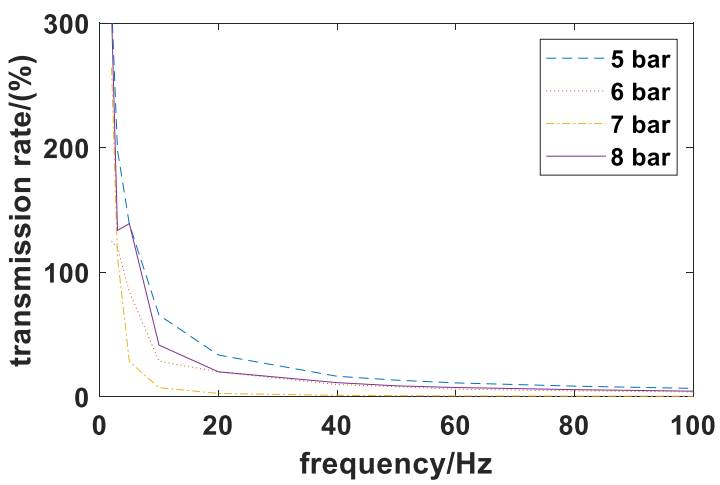

Figure 10. Simulation results under different frequency vibrations.

\subsection{Payload Mass Effect Analysis in Simulation}

The mass of the payload is a constant of $300 \mathrm{~kg}$ in the former simulation. In the dynamic analysis, the payload mass $\left(m_{s}\right)$ is a key parameter and will affect the performance of the spring. In the mass effect simulation, the frame mass is changed from $1 \mathrm{~kg}$ to $300 \mathrm{~kg}$, and the step size is $1 \mathrm{~kg}$. The absolute pressure is set as 1.5, 2, 3, 4, 5, 6, 7, and 8 bar, separately. As can be seen in Figure 11, the frequency of the signal vibration is $50 \mathrm{~Hz}$, and the maximum velocity fluctuation and the transmission rate are the two criteria used to evaluate performance. From the results of the simulation, the two criteria present consistently, and the pressure selected table with different masses is obtained, as shown in Table 3. 

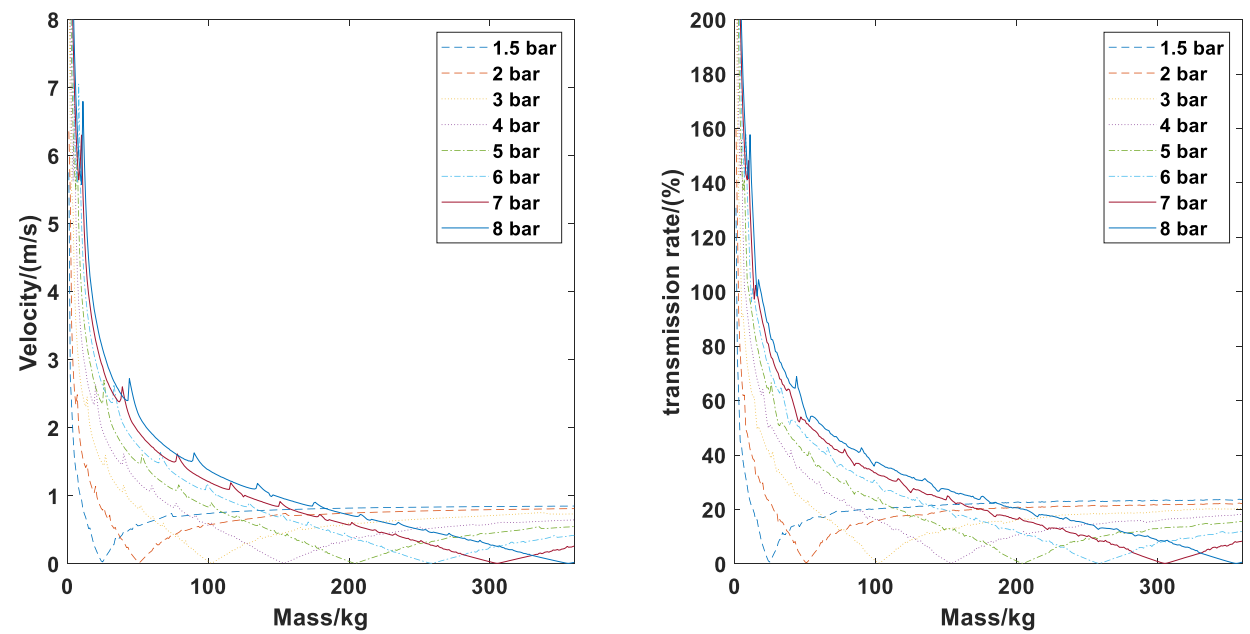

Figure 11. Mass effect simulation under $50 \mathrm{~Hz}$ vibration.

Table 3. Optimal results between the payload mass and the absolute pressure.

\begin{tabular}{ccccccccc}
\hline Payload Mass (kg) & $1 \sim 37$ & $38 \sim 77$ & $78 \sim 126$ & $127 \sim 180$ & $181 \sim 231$ & $232 \sim 280$ & $281 \sim 330$ & $331 \sim$ \\
\hline Optimal Pressure (bar) & 1.5 & 2 & 3 & 4 & 5 & 6 & 7 & 8 \\
\hline
\end{tabular}

In order to analyze the frequency effect, the frequency of the signal vibration is raised to $100 \mathrm{~Hz}$. As can be seen in Figure 12, the two criteria perform better, and the pressure selected table presents consistency when compared with results from $50 \mathrm{~Hz}$ vibration.
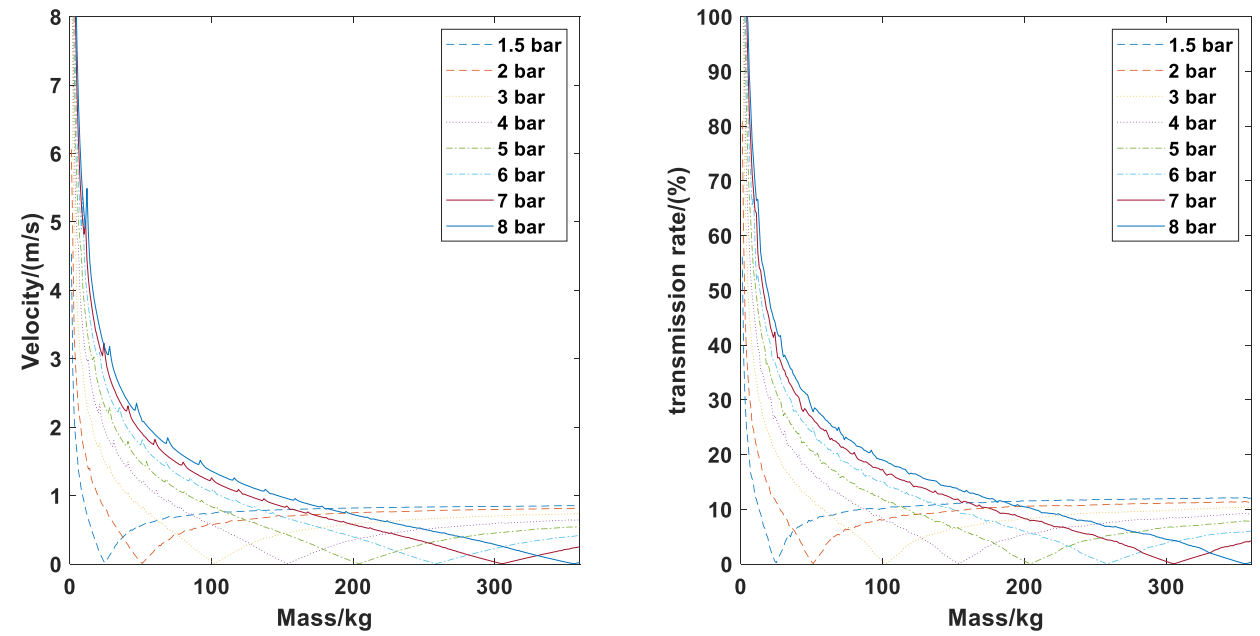

Figure 12. Mass effect simulation under $100 \mathrm{~Hz}$ vibration.

Based on the values from the simulation, a fitting function between payload mass and absolute pressure is achieved to obtain a smaller transmission rate. The applicable pressure value with the payload mass is expressed as:

$$
p_{g}=\frac{50.93+m_{g}}{51}
$$

\section{Validation of the Pneumatic Spring Experiment}

To validate the simulation results, a test prototype of the vibration isolation system is designed and developed. As can be seen in Figure 13a, the prototype system consists of an air compressor to control the pressure of the pneumatic spring, a vibration exciter to produce the vibration wave, a pneumatic spring designed as the novel structure, a 
vibration platform, an isolation platform, and two accelerators to measure the vibration of the two platforms.

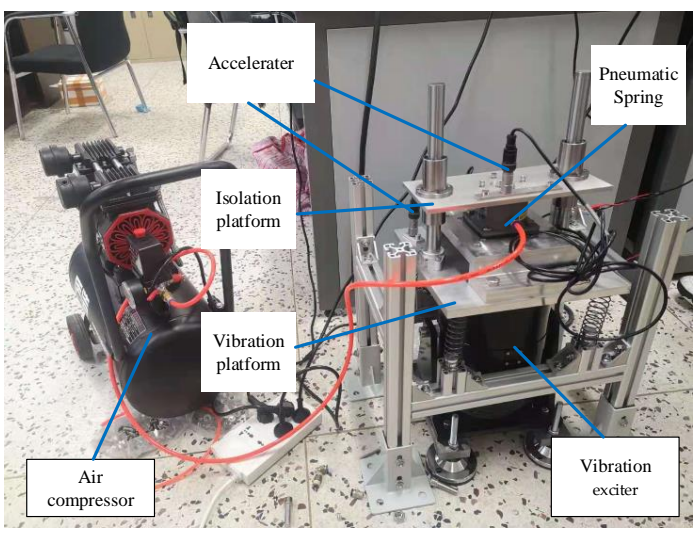

(a)

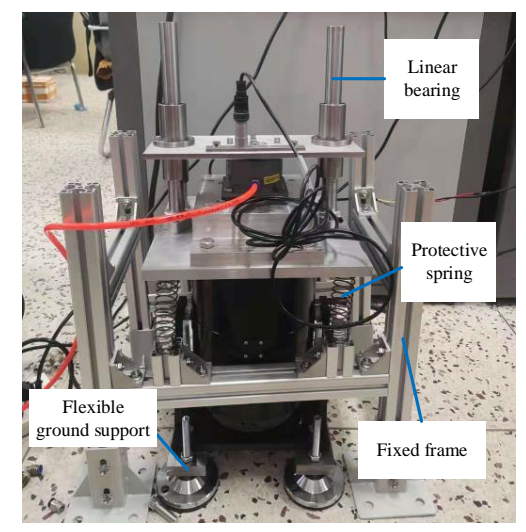

(b)

Figure 13. The test prototype of the vibration isolation system. (a) The vibration isolation system; (b) The vibration isolation platform.

As can be seen in Figure 13b, besides the vibration exciter and the pneumatic spring, the vibration isolation platform consists of flexible ground supports, fixed support, protective springs, and linear bearings. To reduce the vibration transmitted to the ground, four flexible ground supports with rubber pads support the vibration exciter. A fixed frame is assembled from an aluminum profile, and four protective springs support the vibration platform on the fixed frame. This structure shares the load from the vibration platform and protects the vibration exciter. Two linear bearings ensure the transitive vibration direction is vertical.

The mass of the isolation platform is $5 \mathrm{~kg}$. To ensure the effectiveness of the vibration isolator, the transmission rate should be less than $100 \%$. Based on our previous simulation, the pressures of the experiment are set at 1.5, 2, 3, and 4 bar. The vibration frequency is set at 50 and $100 \mathrm{~Hz}$, respectively.

As can be seen in Figure 14, the final transmission rates under $100 \mathrm{~Hz}$ vibration are $41.65 \%, 47.17 \%, 48.36 \%$, and $54.49 \%$ with $1.5,2,3$, and 4 bar absolute pressure, respectively. Compared with the under $100 \mathrm{~Hz}$ vibrations, the transmission rates are $46.81 \%, 52.06 \%$, $61.49 \%$, and $65.75 \%$ under the $50 \mathrm{~Hz}$ vibrations.
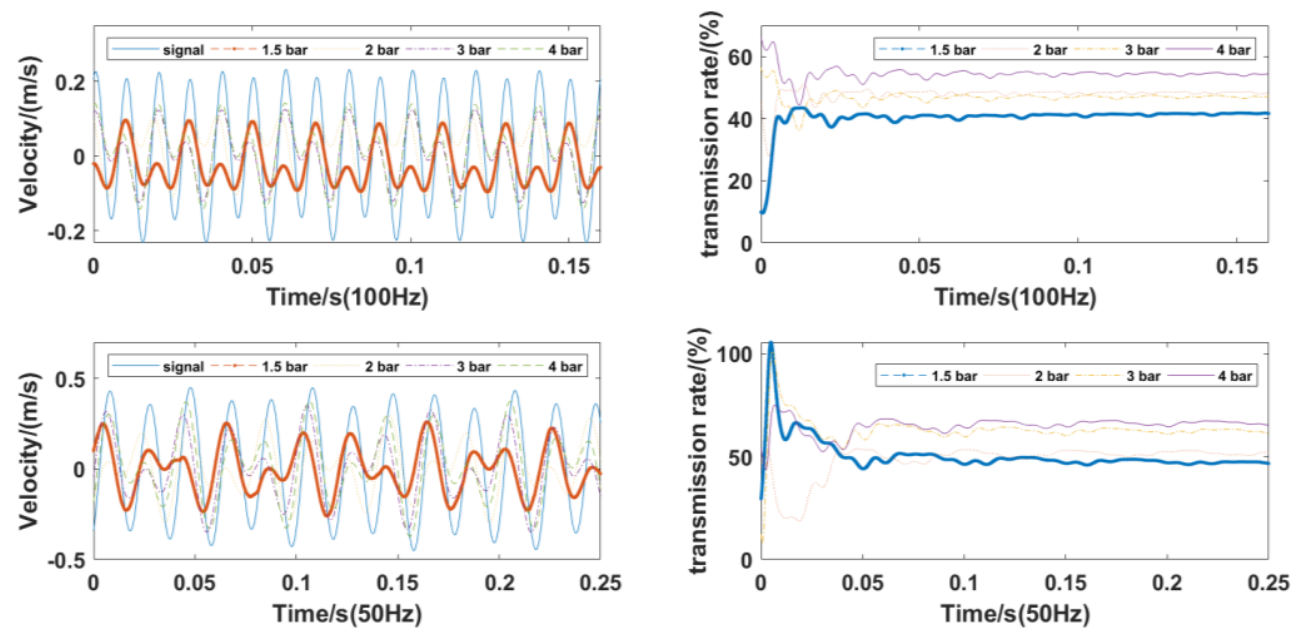

Figure 14. The experiment results from the vibration isolation system. 
In the experiment, when the vibration frequency is under $10 \mathrm{~Hz}$, the isolation platform performs large amplitude vibrations. This proves the passive spring cannot isolate lowfrequency vibrations. The results of the experiment prove that:

(1) The pneumatic spring is effective for vibration isolation under $50 \mathrm{~Hz}$ and, separately, under $100 \mathrm{~Hz}$, both with a $5 \mathrm{~kg}$ payload.

(2) The pneumatic spring performs better with vibration frequencies under $100 \mathrm{~Hz}$ than with those under $50 \mathrm{~Hz}$.

(3) With a $5 \mathrm{~kg}$ payload and the same frequency vibrations, the absolute pressures of the spring from superior to inferior are 1.5, 2, 3, and 4 bar, successively.

(4) For low-frequency vibrations, the passive pneumatic spring is less effective.

The experiment validates the simulation and dynamic models.

\section{Conclusions}

(1) A novel structure of a pneumatic spring is presented. The nonlinear stiffness of the pneumatic spring is analyzed based on the ideal gas model and material mechanics. Natural frequency analysis and the transmission rate of the pneumatic suspension are obtained as two effect criteria using the dynamic model.

(2) The vibration isolation system platform is established using a MATLAB/Simulink environment. With the results from the simulation, the rules of the pneumatic suspension are analyzed. The pressure selected table with different masses is obtained, and the optimal function between the payload mass and the absolute pressure required is achieved.

(3) A prototype of the vibration isolation system is designed and developed. Both the simulation and the experiment prove that our pneumatic spring design is effective at high-frequency vibration isolation - the higher-frequency vibration produced, the better performance the spring shows. For low-frequency vibration, the passive pneumatic spring loses effectiveness. The relationship between payload mass and absolute pressure is validated.

According to the analyzed characteristics, this pneumatic spring can be used for other vehicles or equipment, such as motorcycles or machine tool processing, to reduce high-frequency vibrations. The applicable pressure of the pneumatic spring with different payloads can be determined for better vibration isolation performance based on the relationship equation.

Compared with RLAS, this structure limits the nonlinearity of the rubber. Because it controls the air flow through the air inlet, this structure can be converted into an active suspension for a vehicle. With active suspension, the vehicle comfort should be improved in a low vibration frequency environment. If so, this would become an important basis for future research into improving vehicle suspension and a fundamental theory for the precise control of pneumatic springs in active suspensions.

Author Contributions: Data curation, N.W.; Formal analysis, Z.S.; Project administration, Y.S.; Software, J.Z.; Supervision, Y.S.; Validation, Y.W.; Writing—original draft, Z.S.; Writing-review \& editing, Z.S., Y.W. and S.X. All authors have read and agreed to the published version of the manuscript.

Funding: This research received no external funding.

Conflicts of Interest: The authors declare that there is no conflict of interest regarding the publication of this article.

\section{References}

1. Zhang, J.; Deng, Y.; Zhang, N.; Zhang, B.; Qi, H.; Zheng, M. Vibration Performance Analysis of a Mining Vehicle with Bounce and Pitch Tuned Hydraulically Interconnected Suspension. Chin. J. Mech. Eng. 2019, 32, 5. [CrossRef]

2. Min, Z.; Luo, S.; Chang, G. Research on the mechanism of a newly developed levitation frame with mid-set air spring. Veh. Syst. Dyn. 2018, 56, 1-20.

3. Yang, Z.; Du, Z.; Xu, Z.; Zhou, J.; Hou, Z. Research on dynamic behavior of train dynamic model of straddle-type monorail. Noise Vib. Worldw. 2020, 51, 195-207. [CrossRef] 
4. Gavriloski, V.; Jovanova, J.; Tasevski, G.; Đidrov, M. Development of a new air spring dynamic model. FME Trans. 2014, 42, 305-310. [CrossRef]

5. Gauterin, F.; Sorge, K. Noise, vibration and harshness of air spring systems. VDI Ber. 2001, 1632, $273-285$.

6. Quaglia, G.; Sorli, M.; Guala, A. Air suspensions: Non linear analysis and design considerations. In Proceedings of the Second Internationales Fluidtechniscen Kolloquium (2. IFK), Dresden, Germany, 16-17 March 2000; Volume II, pp. $479-492$.

7. Pradhan, P.; Singh, D. Review on air suspension system. Mater. Today Proc. 2021. [CrossRef]

8. Presthus, M. Derivation of Air Spring Model Parameters for Train Simulation. Master's Thesis, Luleå University of Technology, Luleå, Sweden, 2002.

9. Qian, D. Research on Building Parameter Model, Analysis and Design Theory and Method of Air Suspension of Automobile; Hefei University of Technology: Hefei, China, 2005.

10. Chen, H. Study on Parameters of the Air Spring in Road Friendly Suspension; Guizhou University: Guiyang, China, 2008.

11. Yin, Y.; Rakheja, S.; Boileau, P. A roll stability performance measure for off-road vehicles. J. Terramechanics 2016, 64, 58-68. [CrossRef]

12. Chang, F.; Lu, Z. Dynamic model of an air spring and integration into a vehicle dynamics model. Proc. Inst. Mech. Eng. Part D J. Automob. Eng. 2008, 222, 1813-1825. [CrossRef]

13. Qi, H.; Chen, Y.; Zhang, N.; Zhang, B.; Wang, D.; Tan, B. Improvement of both handling stability and ride comfort of a vehicle via coupled hydraulically interconnected suspension and electronic controlled air spring. Proc. Inst. Mech. Eng. Part D J. Automob. Eng. 2019, 234, 552-571. [CrossRef]

14. Chai, Y. Study on the Mechanical Characteristics of Automobile Air Spring; Hangzhou Dianzi University: Hangzhou, China, 2020.

15. Zhong, Y.; Yang, Q.; Bao, G. Nonlinearity emulation and numerical analyses of pneumatic vibration isolation system. J. Vib. Shock. 2011, 30, 258-263.

16. Moheyeldein, M.M.; Abd-El-Tawwab, A.M.; Abd El-gwwad, K.A.; Salem, M.M.M. An analytical study of the performance indices of air spring suspensions over the passive suspension. Beni-Suef Univ. J. Basic Appl. Sci. 2018, 7, 525-534. [CrossRef]

17. Li, Y.; Huang, X. Vibration isolation design and characteristic analysis for rubber-air spring. J. Mech. Strength 2010, 32, 711-714.

18. Yin, H.; Wu, M.; Du, Y.; Liang, G.; Wei, Y. A predictive method of effective area of rolling lobe air spring for vehicles. Acta Mater. Compos. Sin. 2021, 1-8.

19. Chen, W.; Zhao, L.; Wang, H.; Huang, Y. Parallel Distributed Compensation /Ho Control of Lane-keeping System Based on the Takagi-Sugeno Fuzzy Model. Chin. J. Mech. Eng. 2020, 33, 61. [CrossRef]

20. Yang, K.; Tang, X.; Qin, Y.; Huang, Y.; Wang, H.; Pu, H. Comparative Study of Trajectory Tracking Control for Automated Vehicles via Model Predictive Control and Robust H-infinity State Feedback Control. Chin. J. Mech. Eng. 2021, 34, 74. [CrossRef]

21. Lin, F.; Zhang, Y.; Zhao, Y.; Yin, G.; Zhang, H.; Wang, K. Trajectory Tracking of Autonomous Vehicle with the Fusion of DYC and Longitudinal-Lateral Control. Chin. J. Mech. Eng. 2019, 32, 16. [CrossRef]

22. Pan, H.; Sun, W.; Sun, Q.; Gao, H. Deep Learning Based Data Fusion for Sensor Fault Diagnosis and Tolerance in Autonomous Vehicles. Chin. J. Mech. Eng. 2021, 34, 72. [CrossRef]

23. Sun, X.; Wang, Y.; Cai, Y.; Wong, P.K.; Chen, L. An Adaptive Nonsingular Fast Terminal Sliding Mode Control for Yaw Stability Control of Bus Based on STI Tire Model. Chin. J. Mech. Eng. 2021, 34, 79. [CrossRef]

24. Zhang, L.; Liu, W.; Qi, B. Combined Prediction for Vehicle Speed with Fixed Route. Chin. J. Mech. Eng. 2020, 33, 60. [CrossRef]

25. Szpica, D. Coefficient of Engine Flexibility as a Basis for the Assessment of Vehicle Tractive Performance. Chin. J. Mech. Eng. 2019, 32, 39. [CrossRef]

26. Liu, Y.; Guan, X.; Lu, P.; Guo, R. Research on Key Issues of Consistency Analysis of Vehicle Steering Characteristics. Chin. J. Mech. Eng. 2021, 34, 11. [CrossRef]

27. Zhang, L.; Zhang, Z.; Wang, Z.; Deng, J.; Dorrell, D.G. Chassis Coordinated Control for Full X-by-Wire Vehicles-A Review. Chin. J. Mech. Eng. 2021, 34, 42. [CrossRef]

28. Hao, Y. Research on Air Spring of Low-Frequency and High-Load; Nanjing University of Aeronautics and Astronautics: Nanjing, China, 2007.

29. Yin, Z. Theoretical and Experimental Study of a Dual-Chamber Pneumatic Suspension; Hunan University: Changsha, China, 2012; Unpublished.

30. Zhang, W. Equation of State for Non Ideal Gases. In Modern Practical Pneumatic Technology; Guangdong Chemical Industry: Guangdong, China, 2020; Volume 47, pp. 208-209.

31. Zhuang, B.; Xing, H. Application of nonlinear isolators and define of transmissibility. J. Mech. Strength 1991, 13, 14-17. (In Chinese)

32. Xing, X. Research on Semi-Active Suspension Based on Air Spring and MR Damper; Harbin Institute of Technology: Harbin, China, 2020. 